SULPHURIC ACID SPRAYING OF ONIONS

\author{
By - Mr. T.R. Mundy, Coutts Island; \\ Belfast.

Some years ago, the use of sulphuric acid as a selective reedkiller in onions was discovered, and reports in overseas literature of the success obtained with it led us to try it as a solution of our weed problem.

The areas we have under cultivation all suffer from a severe infestation of fathen. Chickweed, shepherd's purse and speedwell are also troublesome, and we have odd patches of Californian thistle. There is rothing spectacular in the range of reeds present, but to see them grow in the spring is truly spectacular.

our introduction to sulphuric acid spraying is best given by a brief review of our stages of development as onion growers. There are four main stages, and I trust that now we are successfully using sulphuric acid, thern will be no need for a fifth stage.

FIRST STAGE: Some years ago whon we first grow onions, weeds were not a serious problem, for, with the labour force available, we wero able to koep thom under control by hand hoeing and hand weeding. This was so for areas up und around 6 acres.

STCOND STAGE: Later, when we increased the area to 10-12 acres, hand methods could not control the weeds in this area and a light garden tractor was purchased. With knife feeders fitted to this machine and with hand weeding to help out, the weeds were once again under control.

THIRD STAGE: Then the war came and we increased the onion area to 20 acres. Eiven with tractor inter-row cultivators, the small labour force available made the weed control of this area almost impossible, and American Army personnel came to the rescue with the suggestion that we should try selective weedicides. Accordingly, a high gallonage sprayer was built up and some D.N.O.C. purchased. We sprayed it on at the rate of 1 in 100 as per directions on the cans, but made the mistake of putting 1 U.S. gallon in with 99 Imperial gallons, so that the strength of the solution was a little weak. However, even when this fault was corrected results were indifferent. If we sprayed on a hot nor'westery day, the morning spraying was efficient, but in one case 6 acres sprayed after lunch on a very hot day killed all the weeds and also all the onions. We tried pre-omergence spraying, but it was a failure, possibly due to a toxic layer on the surface of the ground still present when the onions emerged. In gencral, we found that the successful use of the $\mathrm{D}, \mathrm{N} \cdot \mathrm{O} . \mathrm{C}^{\prime} \mathrm{s}$. in onions seemed to hinge on a lot of climatic conditions - particularly humidity - that were beyond our control when the weeds needed spraying, and so we passed on to the fourth stage.

FOURTH STAGE: Two years ago we commenced selective weed control using sulcinuric acid. We found it to be highly successful when used intelligently and so far we cannot see anything to supersede it.

TIN SULPHURIC ACID SPRAYER: At this stage I think it would be as well if I doscribed the sprayer we used. A wooden tallow cask was used as a tank and burss and bronze where rigidity was needed and rubber hose where it was rot. The tallow cask was mounted on the back of a Farmall A tractor, which gave us the correct wheel widths to straddle the rows of onions which arc corm in groups of 4 rows. A $I^{\text {"l }}$ bronze gear pump was mounted on the tractor drawbar and driven by a $V$. belt from the tractor pulley. A relief valve was mounted on the delivery line from the pump and the excess spray material ruturned to the tank. A side line onabled us to direct the whole flow from the pump back to the tank through the overflow line as desired, and I will silow you the use of this device later on. Lengths of hose brought the spray f..om the tank to the pump and also delivered it to the boom. The boom was m.de from I" brass tubing and eight inverted U-tubes were bronzed on to carry ight Bordeauz nozzles to spray eight rows of onions over a width of 10 feet. 
The ends of the boom were fitted with removable screw plugs so that it could be thoroughly washed out.

The Bordeaux nozzle was chosen because it is tapered inside and should a blockage occur it is simply overcome by rotating the tap through 180 degrees and the pressure in the boom blows the obstruction clear. A pressure gauge and a control valve on the line between the pump and the boom completes the picture. We did not fit a filter into the system because at the time of building we did not know of a corrosion resistant filter that was fine enough to remove all the fine particles likely to block a nozzle.

PRIOR CULTIVATION AND SOWING: Successful pre-emergence spraying with sulphuric acid can only be obtained by attention to prior cultivation. The land to be sow in onions is ploughed in the winter and left for a while. A month before sowing we topdress vrith manures and lime and then one-way disc to obtain an even distribution of the manure through the top 6 inches of soil. A fine level seedbed is required for inter-row cultivation, so to this end wo disc, roll and harrow. The last implement over the field is a mechanical garden rake which leaves the soil level, fine and firm for the germination of the weed seeds. We leave the ground for 8-10 days and then drill the onion seed. In this way the weed seeds germinate and appear above ground soon after the onions are sown. Onion seeds take just on three weeks to emerge, so 12-14 days after sowing we commence the pre-emergence spraying. The weeds have had just over three weeks to germinate and appear above ground. Under our conditions the weed secds in the top $1 \frac{1}{2}$ inches will germinate in this timo. As we do not oultivate below this depth, the seeds below this are not brought up for later germination. The weeds are now in a very favourable condition for spraying, being strong and growing vigorously. The onions are not yet above ground.

PRE-EMERGENCE SPRAYING: This is carried out 12-14 days after sowing the onions. Our first attempt at spraying with sulphuric acid was with acid of 1.5 specific gravity and for an acre we used 12 gallons of this with 78 gallons of water, plus 1 pint of white spraying oil as a wetting agent. This was to make sure that the small weed seedlings received a fair dose and that the minimum ran off them. Sulphuric acid kills weeds by a process of 'dehydration', drawing the water out of the seedlings faster than it can be replaced by the roots, so that the seedlings wither up and die. So, within economic limits, the more acid on a plant the faster it dies, hence the wetting agent.

Later we found that we got better results with only 9 gallons of acid of 1.7 specific gravity, with 81 gallons of water and the oil. This was a cheaper application per acre and was effective.

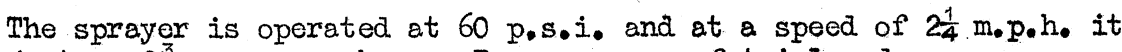
covers just on $2 \frac{3}{4}$ acres per hour. By a process of trial and error over a known distance we found a setting of the Bordeaux nozzle to give a fan jot just meeting between the rows and spraying at the rate of 90 gallons por zcre. Using this technique we found we obtained an excellent kill of weeds. on a hot day with a gentle breeze, when there is a rapid draw off of moisture from the weeds, the results wore spectacular. Twenty minutes after spraying the veeds were bleached white and flat on the ground. Volunteer potatoes that came up after a previous crop turned pink and went mushy and collapsod on the ground. The onions did not suffer because their leaves have a waxy coat and the spray runs off. The best time of the day to spray is in the Leat between $10 \mathrm{a} . \mathrm{m}$, and $4 \mathrm{p} . \mathrm{m}$. If there is dew on the weeds or the temperature is dropping, as it is in the late afternoon, results are indifferent and spraying should be stopped.

With this pre-emergence spraying we were able to kill all the annual weeds above ground and the onions werc free to emerge into weed-free ground. Californian thistle and the potatoes are not killed, but the portions above ground are romoved by the acid. The result of this spraying is that we are able to forget about the onion area for three weeks when the first inter-row sultivation is necessary. Compare this with the old system of top-hoeing. Three weeks away from the crop; at this critical stage it would give the weeds 
such a hold that the area would in most cases have to be abandoned.

We inter-row cultivate the area twice, the machine being fitted with flat knife weeders, and in this way odd weeds are destroyed as they appear in the inter-rows. The ground is not disturbed at any time below a depth of $1 \frac{1}{2}$ inches.

SECOND SPRAYING: When the onions are $4-5$ inches high, that is, when they are well out of the hook stage, wo spray the whole area again, for by this time young weeds are appearing between the onions in the rows, where it is impossible to control them with mechanical means. They are late seedlings germinating after the previous lot were sprayed. This time we still used 9 gallons of acid with 81 gallons of water per acre, but did not use any white oil because this wetting agent tends to allow the spray to sitick to the young onions. As it is, odd spots of acid do stay on the onions and afterwards small bleached spots are seen, but they are of no oonsequence.

The time of this second spraying is variable according to the weed growth present between the onions, but is controlled by two imoortant factors:-

1. The size of the weeds - as with most sprays, the olcer the weods the more resistant they become and the degree of weed control falls off as their size increases.

2. Size of onions - we do not spray the onions after they are 10 to 12 inches high because at this stage of growth the leates twin over and the acid droplets tend to cling to them and buming can result. The onions are only sprayed when the leaves are upright and maximum run-off is obtained.

At this stage I would issue a word of warning about mixing the acid spray solution. The acid must he thoroughly mixed into the watcis. The acid is nearly twice as heavy as water and if it is just poured into a barrel of water, it settles on the bottom. We prepare the spray solution in a separate barrel, half-filling it with water and stirring all the time the acid is added. Then more water is added while stirring continues until the desired volume is obtained. A very important point here is ALWAYS AUD ACID TO THS WATER AND NOT WATER TO THE ACID. When acid is mixed with weter, heat is generated, and if water is added to concentrated acid, heat is sonerated so quickly that water is turned into steam and the whole lot can blow up. Concentrated acid in the face can result in blindness and screre burning of both skin and flesh.

When the sprayer comes back for a refill, we do not pour the acid solution into the tank, but make the machine fill itself. Whe intake hose from the tank to the pump is put into the barrel of prepared spray. By diverting the output of the pump through the sideline I mentionod. carlier, the contents of the barrel are soon pumped direct into the sprayer's tank. In this way the dangor of splashes from bucketing $10 \%$ sulphuric acid is overcome.

SUBSEQUENT WHIDING: After this second spiaying we go through the onions twice with the inter-row cultivator to pick up odd weeds in the inter-rows, The cultivator is not used efter the onions reach the kulbing stage. As required, a gang of three men and 5 boys goes over the aree to remove by hand the weeds between the onions. Some areas need no hanc. weeding at all; in others we are able to walk across the area and attend to tho odd weds that occur. In other aroas asain, whore weeds are bad due to biockea nozzles or some other rcason, it is a case of getting aow on the knees and getting into them. Fowever, I am glad to say that since the adoption of acid spraying the time spent on the kneos is at an absulute minimurn. The weeds that wo do attend to by hand are not removed because of the competition they offer to the growth of the onions, but because they are an obstruction in the mechanical harvesting of the onion crop, We do not pull one onion by hand. The whole thirty acres is harvested by machines and, of course, they work best in a weed free crop. 
PRECAUTIONS TO BE OBSERVED IN HANDTING SULPHURIC ACID: I have already mentioned the very important rule of ADD ACID TO WATER AND NOT VICE VERSA. This cannot be stressed too strongly. Other precautions we observe are to wear goggles when mixing the acid so that in case of odd splashes, the eyes are protectcd; a bowl of baking soda solution is kept handy so that splashes on the face are readily neutralised; the operator who is handy at all times to attend to blocked noriles shovid they occur, wears gumboots, for we find that the acid spray eats away the stitches in leather boots and they fall apert. In fact, we botis wear gumboots. We also wear woolln clothing because the acid eats holes in cotton garments. It is a good idea to smear a little vaseline on the arms, face and neck, because wind drift from the nozzles on a slightly breezy day can be irritating, if not harmful. Taking these few precautions, sulphuric acid is not dangerous to use and we have no trouble with it.

After the spraying is over, the sprayen is washed out well with water and finally with a solution of washing soda at 2 pounds per gallon to neutralise any traces of acid romaining in it. The whole of the exterior of the sprayer and tractor are tho:roughy hosed down.

STMMTNG UP: We are conrinced that sulphuric acid is the best means of killing weeds in onions and we are sorry that we did not use it earlier than we did. It would have saved a lot or ha $=$ d work. Provided it is used intelligently and attention given to the main points I have made earlier, sulphurio acid will give $100 \% \mathrm{kill}$ of the annual weeds above ground at the time of spraying and the onions suffer no detrimental damagc. I say no detrimental damage, because the few odd spots oi bleaching on odd leaves are of no consequence and do not impeir the plant:s growth.

COSTS: So much for the spraying programme and the results attending it. The big question that is going through your minds is "What does all this cost?" Well, we had the acid sprayed made up. in a local workshop and for ease of working I have valued it at £50. It may ac'ually cost less than that, but at the somo time is worth many nore times that to me.

Sulphuric acid of 1.7 specific gravity costs $13 / 6 \mathrm{~d}$. per cwt. and we use 9 gallons or about $160 \mathrm{lbs}$. per acre at a cost of about $19 / 6 \mathrm{~d}$. per acre. Twice over the area and paying ourselves wages, allowing for overhead on the plant and for petrol and oil, the total cost for the two sprayings is $\$ 2.3 .6$ por acre.

Valuing the inter-row cultivator at $\&_{4} 0$ and taking into account wages, overhead, petrol and o:I, the total cost of the four cultivations is $\$ 2.3 .6$ per acre.

We employ a gang of 3 men and 5 schoolboys for three weeks to hand weed the onions, and whilo it could be argued that part of this cost could be charged to the harvesting of the crop because it is cemied out partly for sase of mechanical harvesting, wo will absorb it all into the weeding programme. This works out at 32 hours per acre, and allowing for men's wages at $3 / 8 \mathrm{~d}$. and schoolboys' at $2,16 \mathrm{~d}$, costs 24.14 .0 per acre.

The grand total for our various wectirig operations is $\$ 9.1 .0$ per acre.

Now compare this with hand methods of weed control, using the knife, the hand hoe and the whecl 1 . I. It has been established that the average crop of onions takes 65 houns of hand weeding, 20 hours of hand hoeing, and 25 hours of wheel hoeing per acre. Costing this out at $3 / 5 d$. per homr, the grand total is $\$ 18,16.0$ per acre por labour. The cost of the plant is of course negligible.

The advantages from the economical rierpoint of our system of acid spraying are that we have reduced the cost of weeding from \&l8.16.0 per acre to $\$ 9.1 .0$ per acre, or a saving of just over $50 \%$ on the hand weeding programmo. From the prac'sical point of view the time spent in hand weeding that j.s, actually on the lneos - has been reduoed from 65 hours to 32 hours per acre, or just half the timo. I think you will agree that this is perhaps the greatest saving of all bccaust, we are enabled to do other worts at a busy time of the year. 


\section{QUESTIONS AND DISCUSSION}

MR. GREEN: We have not done much commercial spraying of onions, but where it has been done DNOC has been used and gives good control. We sow in the autumn and are spraying from about July until mid-Ootober. We worked out a technique of spraying with kerosene, about 30 gallons to the acre. While the onions are in the ground we find we can spray quite safely. We tried sulphuric acid, with quite good results, but we gave up because very few farmers were equipped with acid resistant equipment. We are now trying a new weed killer, potassiurn cyanide, which is giving good results in the United States. We have that going this year.

MR. SIMPSON: Have you had any experience of spraying seed onions?

MR. MUNDY: No, but I have heard that they can be sprayed, but only at certain stages. Once the leaves bend over you can do serious damage.

MR. JOHNSON: How does the controlled area compare with the sprayed area for yield?

MR. MUNDY: If anything, the sprayed area gives a slightly heavier crop than the other. There is a certain manurial content from the spray. 